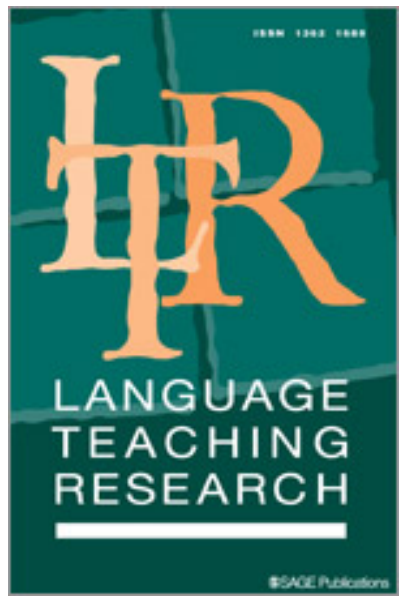

\title{
Rise to the Occasion: The Trajectory of a Novice Japanese Teacher's First Online Teaching through Action Research
}

\begin{tabular}{|c|c|}
\hline Journal: & Language Teaching Research \\
\hline Manuscript ID & LTR-18-0393.R2 \\
\hline Manuscript Type: & Practitioner Research \\
\hline Keywords: & $\begin{array}{l}\text { novice teacher, distance education, standard-based curriculum, Japanese } \\
\text { teaching, multimodal digital tool, virtual mentoring, pedagogy, } \\
\text { professional development, foreign language teaching, action research }\end{array}$ \\
\hline Abstract: & $\begin{array}{l}\text { Foreign language teaching in distance education is administratively and } \\
\text { pedagogically challenging; research on the perspectives of novice } \\
\text { practitioners' online teaching is also relatively scarce. This study explores } \\
\text { how a novice Japanese teacher navigated and negotiated her } \\
\text { professional development in a two-way virtual practitionership during her } \\
\text { first online teaching. Data were collected from ongoing dialogue journals } \\
\text { between the novice and her mentor followed by a semi-structured } \\
\text { interview. Qualitative results indicate that pedagogically-sound and } \\
\text { personalized digital tools can not only reduce the psychological distance } \\
\text { between the teachers and students, but facilitate online teaching and } \\
\text { learning via a performance-driven, standard-based curriculum. Informed } \\
\text { by Action Research, the study reveals how both practitioners } \\
\text { de/reconstructed their teacher identities and achieved professional } \\
\text { empowerment through robust supervision and reciprocal teacher } \\
\text { evaluation in a virtual environment. It further demonstrates the extent } \\
\text { to which this evidence-driven and research-oriented approach can better } \\
\text { address the genuine concerns of a foreign language program in distance } \\
\text { education. Specifically, this context-responsive study indicates the } \\
\text { improvement of online course delivery, teacher training and program } \\
\text { sustainability in its own right. }\end{array}$ \\
\hline
\end{tabular}

\section{SCHOLARONE


This is the accepted version of the manuscript submitted to Language Teaching Research. For the final published version, please refer to https://doi.org/10.1177/1362168819846794 


\section{INTRODUCTION}

Recently, a growing number of universities have embarked on distance education to offer learning accommodation and flexibility for regional and remote students who cannot attend regular classes on campus (Hartshorne et al., 2013). Transferring under-enrolled language courses from the traditional face-to-face $(\mathrm{F} 2 \mathrm{~F})$ mode to the fully online mode is hence gaining its momentum in higher education (Blake, 2013; van Deusen-Scholl, 2015). Despite the popular demands, challenges also confront the actual implementation and content delivery in practice. Whether or not a fully online foreign language course will run successfully often depends on the availability of a suitable teacher who is wellversed in both pedagogy and technology. Some language teachers may have prior online teaching experience using conventional learning management systems (LMS) tools such as discussion boards. However, they may not be familiar with utilizing technology that affords multimodal communication (e.g., VoiceThread (VT) or mobile applications) to enhance telepresence and copresence (i.e., the sense of being there together) while minimizing the psychological distance (Authors, 2017). Furthermore, studies on the training of online instructors of foreign languages are also quite limited (see Guichon, 2009; Jimenez and O'Shanahan, 2016).

This study reports on how a novice Japanese teacher navigated through her first online teaching in an intensive summer Japanese beginner course and developed a sense of professional empowerment and achievement. Drawing on action research (AR) (Allwright, 1997, 2003; Burns, 2007, 2010, 2011, 2013, 2015; Kemmis and McTaggart, 1988), it documents an ongoing, two-way practitioner mentoring between a novice and an experienced teacher of Japanese in distance education and examines how her teaching apprenticeship evolved in a virtual environment. Collectively, both novice/mentor practitioners constantly adjusted and reflected on their own teaching approaches and negotiated their stances through self-/peer evaluations and lessons learned from tackling instructional challenges. Their growing realization of becoming professional teacher practitioners exemplified the best practices in language teaching in a digital context. Data were collected from extensive dialogue journal exchanges between the novice teacher and her mentor. A semi-structured interview was conducted to better understand her debut in online teaching using multiple digital tools and attitudes toward a standardbased, performance-driven curriculum versus a traditional approach. Suggested teaching strategies developed to resolve issues in teaching a fully online course were also offered for like-minded teacher researchers.

\section{RESEARCH BACKGROUND}

\section{Teaching Japanese online in the U.S.}


Since online instruction can overcome the constraints of time and distance and alleviate the enrollment issue, many higher education institutions are encouraging their faculties to develop online courses in the past few decades. However, psychological distance that typically arises in distance education particularly disadvantages foreign language teaching (Oliver et al., 2012). To mitigate the sense of isolation in distance learning, a fully-online language course benefits from a standard-based curriculum design that can facilitate the execution of assessments and enhance the delivery of digital technologies (Authors, 2015a, 2015b). The American Council on the Teaching of Foreign Languages (ACTFL), for example, outlines a performance-driven benchmark to connect classroom practices to "can-do" descriptors that are meaningful to learners at various target proficiency levels (Adair-Hauck and Troyan, 2013). ACTFL's Integrated PerformanceBased Assessments (IPAs) are fully aligned with the World-Readiness Standards for Learning Languages (WRSLL), targeting five core areas: communication, cultures, connections, comparisons, and communities $(5 \mathrm{Cs})$. These $5 \mathrm{Cs}$ have been integrated in foreign language teaching and aligned with IPAs to assess how learners deploy linguistic and cultural competence for authentic and real-world tasks in the three modes of communication: interpretive, interpersonal, and presentational. This also serves as a pedagogically-sound framework for curriculum design in online language teaching.

Teaching Japanese online in the U.S. context faces additional challenges. Japanese is a non-cognate of English with distinct structures, lexemes, non-Roman scripts, and different socio-cultural values that shape the norms of language use. It is categorized among the most time-consuming languages to learn for English speakers (Category IV languages) by the Foreign Service Institute of the United States. Thus, teaching Japanese demands more pedagogical attention, let alone teaching in an online setting. Research on online Japanese instruction ranges from satellite/televised Japanese instruction (Kataoka, 1986; Kubota, 1999; Yi and Majima, 1993), multimodal tool applications for online college Japanese courses (Authors, 2015a, 2015b, 2017) to the effectiveness of digital technology for teaching kanji characters (Nesbitt and Muller, 2016; Mori et al., 2016).

To date, studies focusing on the experiences and perspectives of online teachers of Japanese are relatively scarce. An exception is Shibakawa's (2018) recent study conducted in a two-year college in North America. She investigates how a Japanese teacher's beliefs in online Japanese teaching were shaped by formative and design experiments where the teacher and the researcher collaboratively created an intervention plan to improve online Japanese teaching and observed its outcomes, similar to the approach of action research (AR). In the context of English as a foreign language (EFL), Kaiser (2017) provides an overview of the Ceibal en Inglés (CEI), a large-scale program organized by the British Council for teaching English remotely to students in Uruguay via interactive videoconferencing where the teachers were located all over the world (i.e., Argentina, Philippines, United Kingdom, Uruguay). The CEI program provides a sustainable model to tackle the shortage of qualified English teachers in Uruguay via distance learning. Guided by AR, Rovegno and Pintos (2017) engaged groups of CEI teachers in their study and those teachers regularly debriefed with their peers face-to-face at meetings and events regarding the AR implementation. They found that AR was not only conducive to the development in acquiring new teaching skills and learning new 
digital tools, but also supporting them and reducing anxiety while exploring different teaching interventions. However, it is still unclear if teacher professional development for online language teachers can be realized in a fully online context. It is also worth investigating how mentor teachers with extensive classroom teaching experience can reciprocally learn from mentoring in online contexts when they themselves are also relatively new to online language teaching.

Given the urgent demands of training new teachers of online Japanese courses, it is crucial to better understand the difficulties faced by novice Japanese teachers in online instructional environments and offer context-specific mentoring support by teacher trainers. Reciprocally, mentors can also learn from mentoring the novices virtually while providing a two-way mentorship model for online Japanese programs.

\section{Action Research (AR)}

Arguing that teachers can also contribute their professional expertise, unique perspectives and practical experiences to classroom-based research, AR has received growing popularity with teacher practitioners and acceptance as a legitimate research-based inquiry in the field of applied linguistics and language teaching (Burns, 2011; Edwards and Burns, 2016a; Mackey and Gass, 2015). Engaging teachers in the AR process not only allows their voices to be heard and valued but makes research findings more applicable to teachers' context-specific situations than research solely conducted by "outsiders" or not closely relevant to their everyday practices (Alwright and Bailey, 1991; Crookes, 1993). This active and inclusive research approach renders ownership back to the practitioners, thus empowering teachers' agency and rebalancing researcherpractitioner equality (Greene, 2006; Goodnough, 2010). Accentuated by its empirical and practitioner-oriented nature, AR advocates the "teacher-as-researcher" agenda concerning practitioners' inquiries into a local problem and promoting participatory collaboration negotiated between teachers and researchers (Edwards and Burns, 2016b), thereby fostering teacher professional development and situating context-responsive findings through reflective practices and systematic interventions (Alwright, 2003; Burns, 2011, 2015). By the AR token, related terms are also adopted by action researchers, such as participatory action research, critical action research, exploratory action research, participant inquiry, practitioner inquiry/research, cooperative inquiry/research and teacher research (Burns, 2015; Mackey and Gass, 2015). In sum, AR can be conceptualized as

a self-reflective, systematic and critical approach to enquiry by participants who are at the same time members of the research community. The aim is to identify problematic situations or issues considered by the participants to be worthy of investigation in order to bring about critically informed changes in practice (Burns, cited in Cornwell, 1999: 5).

As the term action research entails, teacher researchers are both active participants (in the action) and critical investigators (of the research). Integral to AR is a systematic and dynamic process initiated by teachers and facilitated by researchers to problematize the status quo through identifying a "puzzling issue" (Alwright, 2003: 124) in a localized 
context (be it a classroom or a community), finding solutions to what is not working and bringing changes to the immediate concern impacting the stakeholders (e.g., students, teachers, principals, academics; Creswell, 2012; Burns, 2015). Once a practical problem (or a "puzzle", a term closer to exploratory practice in the realm of practitioner research; Alwright, 2003) is identified, action researchers aim to resolve the pressing issue by systematically making a plan to improve the situation, acting on the plan by gathering context-responsive data, observing the implementation outcomes and reflecting and evaluating its effectiveness before taking further informed actions or making recommendations to the stakeholders involved (Burns, 2010; Kemmis and McTaggart, 1988). Therefore, this cyclical process that spirals back and forth each stage of AR investigation is pronounced in its dynamic movement, adaptability and reiteration to bring out immediate benefits to better teaching and learning (Creswell, 2012). The end results of AR, hence, can maximize the quality and sustainability of a localized entity (e.g., class, program, school) and satisfy the urgent needs of both teachers (who can find solutions to improve teaching and student learning) and researchers (who can study a real-world problem and disseminate evidence-based, context-responsive findings) (Allwright, 1997). Furthermore, being fully committed and engaged in the AR process has a transformative impact on the development of teachers' identity and self-efficacy - it whets teachers' appetite for doing more research as emerging researchers (Edwards and Burns, 2016a, 2016b; Goodnough, 2010; Yuan and Burns, 2017).

Notably, AR in language teaching is predominately classroom-based research since the mainstream venue of lesson delivery is generally conducted in a physical classroom or school (Alwright and Bailey, 1991; Creswell, 2012; Crookes, 1993; Burns, 2007, 2010, 2013, 2015). Situated mostly in ESL/EFL contexts, prior AR studies have centered on the construction of teacher researchers' sense of agency and identity negotiated in their workplace (Edwards and Burns, 2016b; Yuan and Burns, 2017), teacher professional development shaped by their AR engagement (Burns, 2011; Wang and Zhang, 2014), the effects of collaborative AR on the development of learners' language production and motivation via curriculum intervention (Banegas et al., 2013; Sowa, 2009) and AR recommendations for quality and sustainability of language programs (Allwright, 1997; Edwards and Burns, 2016a). While these positive outcomes highlight the empowering potential that AR can bring to both researchers and practitioners, research targeting novice language teachers' online teaching practices in distance learning and how AR can transform their self-efficacy beliefs and professional development is still less explored (cf. Kaiser, 2017; Rovegno and Pintos, 2017), let alone online Japanese teaching (see Shibakawa, 2018). This concern propelled us to embark on an action plan operated in a virtual environment and to disseminate findings drawn from an online Japanese teacher's case study in order to enrich the AR literature.

\section{RESEARCH QUESTIONS}

The core inquiry of the study is how to improve the quality of the current online course and provide better services for the stakeholders, such as content delivery for the students and teacher training for online instructors and mentors. Another line of inquiry is how to establish program sustainability through evidence-based practices that could feed back 
into future curriculum design and online course delivery. Hence, two pertinent questions are raised:

1. What is the novice teacher's perspective of teaching a performance-driven, technology-enhanced curriculum in a fully online environment?

2. How does AR play out in a virtual environment for the professional development of both novice and mentor teachers?

\section{METHODOLOGY}

\section{Setting: Online JPN 111}

This intensive online Japanese course for beginners (JPN 111) was offered at a public university in the Northeastern United States in summer 2017. It was first launched in summer 2015 and initially taught by the Japanese mentor teacher, who is also one of the researchers in this study. Currently, all online courses are parallel to their F2F counterparts regarding contents and assessments as required by the university. This online course was designed following the ACTFL's 5Cs (see above) targeting the novicelow to novice-mid ACTFL proficiency level (ACTFL, 2015). While Blackboard as the LMS was the central portal for this online course, asynchronous and synchronous tools that were previously piloted by the mentor teacher were adopted: Google Documents (GD), VoiceThread (VT), and Google Hangouts (GH). GD, as editable digital worksheets, was incorporated for students to practice writing and reading comprehension exercises at their own pace and to receive feedback from the instructor and teaching assistants (TAs). $\mathrm{GH}$ was adopted for TAs to regularly conduct real-time group sessions to help students practice conversation in Japanese. It was also used for the instructor to conduct virtual office hours and two oral interview sessions to assess students' oral proficiency, grammar and vocabulary knowledge. VT, as a multimodal digital platform, allows users to create postings and provide/receive comments in various forms (images, texts, audios, video clips, documents and doodling). Lesson-related slides were uploaded to VT as prompts for students to audio-record comments using a built-in microphone in their own device, or videorecord comments using a camera. Students also kept a learning journal and shared it with the instructor through Blackboard.

\section{Participants $^{1}$}

Two instructors of Japanese, both of whom are native Japanese speakers, collaborated for teaching this intensive, fully online course. The novice teacher (Hana) had no prior Japanese teaching experience before 2015 while the experienced teacher (Noriko) had nearly two decades of teaching experience in F2F contexts. In summer 2015, they were both new to online teaching when they first taught this summer course, during which Noriko served as the instructor while Hana was recruited as one of her TAs. After experiencing teaching F2F elementary Japanese elsewhere, Hana started taking a few workshops for online teaching, and finally served as the instructor for this course in 2017 under Noriko's supervision as a mentor/researcher. Even though Hana was new to teaching a standard-based, performance-oriented course, she continued to discuss with 
Noriko the updates in the syllabus and course pack, issues arising from assessments and projects, TA coordination, implementation of digital platforms and teacher reflection. Revised each semester, the course pack (created by Noriko) covers communicative tasks and explanations on basic vocabulary, grammar, orthography and culture for beginners.

\section{Data collection}

Qualitative data were collected throughout this six-week intensive online course in which 27 students were enrolled. Noriko and Hana developed an ongoing mentorshipapprenticeship dialogue via journal exchanges. After each online session, Hana would reflect on challenges encountered in her lesson, observations of student learning progresses and outcomes, advice needed regarding the actual delivery of content and performance tasks, or lessons learned from instructional adjustments. GD was utilized as a shared space for journal exchanges. They typed mostly in Japanese, where Hana typed in black and Noriko replied in pink, and their exchanges were later translated into English (approximately 12,000 words in length) (See Figure 1).

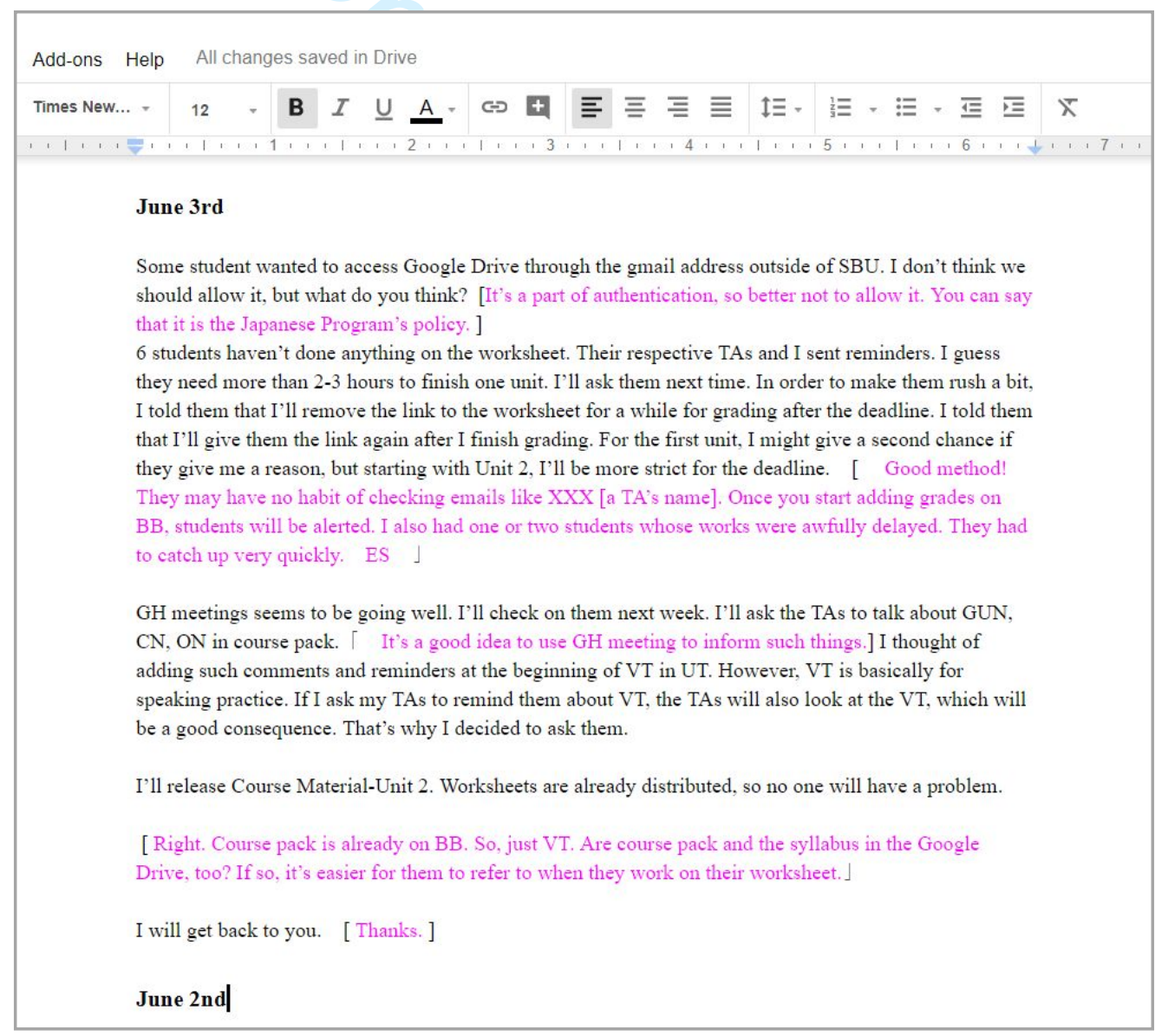

Figure 1. A screen capture of the dialogue journal exchange between Hana and Noriko on GD 
This approach allowed Noriko to conduct close participant observation (Creswell, 2013) as a mentor, which further mirrored the essence of participatory and context-responsive action research. We adopted the standard AR cycle model proposed by Kemmis and McTaggart (1988), consisting of four essential phases: plan, act, observe and reflect. As Burns (2010) argues, this classic model is commonly used in AR and easy to follow as a guide, especially for teacher researchers who are new to AR. Figure 2 illustrates how the data collection and dissemination were conducted following the systematic AR model. Action taken in each phase was built on the previous data gathered, observations of the implementation plan and reflections/evaluations of the outcomes before further adjustments or recommendations could be made: ${ }^{2}$

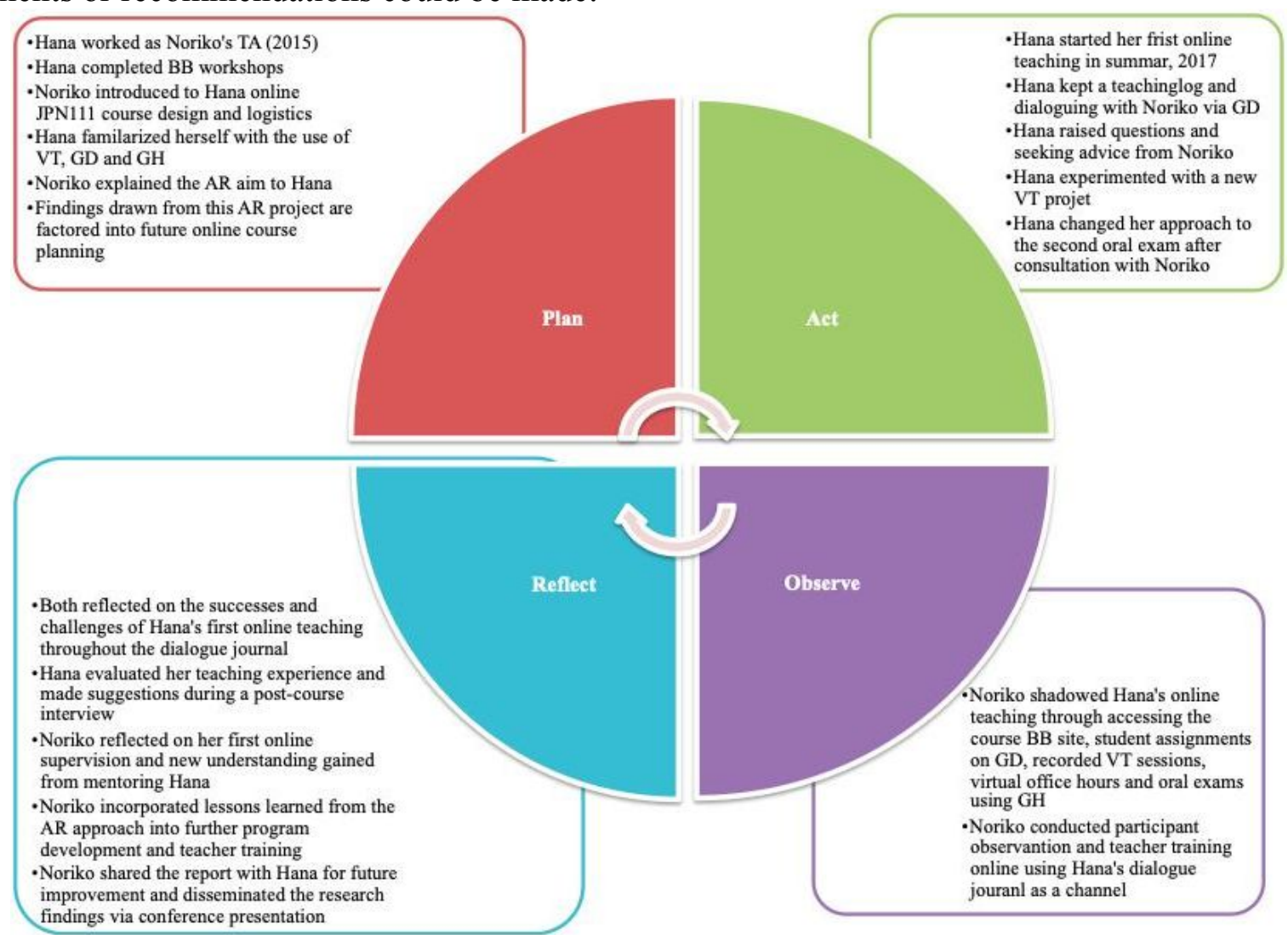

Figure 2. A visual representation of the study following an ongoing and systematic AR cycle

To provide another retrospective dimension of the novice teacher's perspective while mitigating the mentor teacher's direct influence on her, the second author of this study conducted a semi-structured interview with her at the end of the course (see Figure 3): 
1. Can you describe your prior online teaching experience?

2. How was your workload of this course?

3. How do you compare face to face teaching and online teaching?

4. What were the successes of this online course?

5. What were the challenges of this online course?

6. Have you used GD, VT, GH in your prior online teaching? What features did you find useful (or not) for Japanese teaching and learning? Can you give some examples?

7. Will you consider using them again in your next online course? How would you use them differently next time?

8. It seems that you're quite skilled in using BB. What role does it play in this course? How did you compare it with GD/VT/GH when it comes to online teaching this time?

9. You came up with the VT project for this online course. How did you like it? Were you able to know whether or not students invested a lot of time and effort in their VT projects?

10. Regarding the two oral tests. Can you share your thoughts about them? What would you have done differently next time?

11. Finally, what lessons have you learned from this experience? Do you have other comments or suggestions as well?

Figure 3. Semi-structured interview questions

To ensure dependability of the interview (Creswell, 2013), all the questions had been discussed and revised between the two researchers to eliminate wording ambiguities in advance of Hana's interview. For the sake of practicality and face validity (Merriam, 2009), the videoconferencing interview was originally conducted via GH since the interface and features were already familiar to her. However, the screen capture software only recorded the first 10 minutes of the interview. To tackle this issue, a follow-up interview was immediately set up via GD, considering that Hana's memory was still fresh and GD allowed her to take time to reflect more deeply on those interview prompts.

\section{Data analysis}

A thematic analysis approach (Merriam, 2009) was employed for data analysis. Each researcher constantly read all the journal entries and interview transcript to make sense of the data and gain a general picture of the investigated phenomenon. Going back and forth between and across the data, both researchers assigned in vivo codes (i.e., "exact words used by participants," Creswell, 2013: 185) to label keywords repeatedly arising from different sections of the dataset. The recursive process operated continuously through the dataset, subsuming labels that pointed to the same pattern, identifying major themes by foregrounding related patterns into more illuminating categories, and consequently collapsing all the themes into a higher-level conceptual theme. Verbatim quotations drawn from the dialogue journal and interview were identified as evidence to illustrate and support the associated patterns and thematic categories.

Although the inductive analysis approach was adopted during this ongoing and iterative process and no predetermined categories were applied before coding, we nevertheless acknowledge that thematic patterns induced from the data could still be influenced by both researchers' own interpretations and experiences (Burns, 2011; Mackey and Gass, 2015). That said, we equally coded the data, compared initial coding, resolved coding discrepancies, and captured the essence of corresponding data to develop thematic categories (i.e., cross-checking perspectives; Burns, 2015). To validate the research 
findings, we also conducted member checking to share with Hana the initial emerging themes and pattern interpretations (Merriam, 2009). Her suggestions and views about the accuracy of the preliminary findings were factored into further thematic modifications to account for the rigor and credibility of the study (Creswell, 2013).

\section{FINDINGS}

Following a systematic analysis and thorough examination of the journal exchanges, corroborated with Hana's interview transcript, two key thematic categories were identified:

1. Attitudes toward incorporating digital tools in Japanese instruction

2. Enrichment of teaching repertoire through reciprocal mentorship and apprenticeship in AR

These themes accentuate how she evolved and enriched her teaching skill set vis-a-vis challenges encountered while positioning her teacher identity from a novice to an experienced--shadowed and nurtured by Noriko throughout her online teaching journey. Each research question is addressed by its related theme(s) and categorized by corresponding thematic patterns (see Table 1), which are further illustrated by verbatim evidence to capture nuances of the investigated phenomenon.

\begin{tabular}{lll}
\hline \multicolumn{1}{c}{ Themes } & \multicolumn{1}{c}{ Patterus } \\
\hline $\begin{array}{l}\text { Attitudes toward incorporating digital } \\
\text { tools in Japanese instruction }\end{array}$ & - & Blackboard LMS: Learning analytics \\
& - GH office hours: Real-time personalized \\
& consultation \\
& - & VT project: the "aha moment" \\
\hline $\begin{array}{l}\text { Enrichment of teaching repertoire } \\
\text { through reciprocal mentorship and }\end{array}$ & - Self-doubt of the novice: Advice seeking \\
apprenticeship in AR & in apprenticeship \\
& Instructional adjustment through teacher \\
& self-evaluation \\
& Virtual supervision: Mentor shadowing, \\
& debriefing and evaluating \\
& Mutually inclusive mentorship: AR
\end{tabular}

Table 1: Summary of key categories associated with thematic patterns

\section{Attitudes toward incorporating digital tools in Japanese instruction}

\section{Blackboard LMS: Learning analytics}

Blackboard (BB) was used as the LMS in addition to multiple digital tools (GD, GH and VT) in this online course. As it was Hana's first time utilizing these platforms, information about comparing the technological functionalities from the perspectives of a novice teacher is insightful. Considered as tech-savvy, she had completed workshops on utilizing BB features before this online course. With knowledge and skills learned in 
those workshops, she used BB's analytics data to discover the patterns and frequencies of students' BB activity logs, such as "what time majority students started studying (viewing materials), how long it took for each task, which day of the week they started working on the new unit... its retention center gave me lots of information about students' progress" (interview, 08/10/2017). Another advantage of BB is that she could instantly record grades in Grade Center, integrate Google calendar into BB to remind students of assignment due dates or release each assignment packet unit by unit, which Noriko did not perform back in 2015 .

\section{GD commenting feature: Continuity}

Although BB has a viable learner analytics mechanism that statistically generates user activity reports, Google Drive's activity history tracks all the progress of students work on GD in real time. Because Hana and her TAs regularly reviewed students' digital worksheets through GD, the user activity history generated by Google Drive was useful to know when to check those worksheets. After experimenting with both BB and GD domains, Hana reflected in her journal (06/27/2017) that GD was more user-friendly than BB as typing in Japanese in GD was much easier. She went on to comment that students couldn't automatically receive notifications from BB discussion board whereas they could view the real-time activity history that shows up and stays on the sidebar of Google Drive, thus maintaining "continuity" in the flow of online discussion between each student and herself. Students were also familiar with Google Apps notifications for personal communication outside academic work. As evidenced in her journal entry (06/27/2017),

GD allows me to respond to students more quickly, creates "continuity," and makes typing in Japanese easier. At this level (JPN111), my comments in Japanese tend to be short (e.g., "Ganbarimasho!" Try your best!), but when I must explain in Japanese, changing fonts to Japanese in [BB] is troublesome. So, I always type in Word, and then copy and paste what I typed on BB.

Hence, the sense of "continuity" afforded by GD creates the sense of "connection" and keeps the flow going more smoothly, thus removing the "rigid" feel (which is typically felt on BB) and promoting lifelong learning in a user-friendly environment. As long as students work on GD, their instructor can constantly stay tuned and virtually connect with them.

\section{GH office hours: Real-time personalized consultation}

GH was implemented to help students practice speaking in Japanese with TAs and consult with Hana during her virtual office hours. Compared with the videoconferencing feature on BB, GH "is eas[ier] to use...[and] more accessible" (interview, 08/10/2017). Throughout the course, students were more used to GH and preferred using this synchronous tool to have their inquiries promptly addressed by TAs or Hana in real time, than waiting for the reply via email or the asynchronous discussion board. Hana reflected on how her GH sessions not only helped her troubleshoot student concerns in comprehending content materials, but also shortened the psychological distance typically experienced in distance learning (Oliver et al., 2012; Nielson et al., 2008; Shea et al., 
2005; Warriner-Burke, 1990; Authors, 2017): "Unit 1 Review [GH office hours] was very useful because I could understand the points that they [were still struggling with]...I could see all students who are working on the course, finally" (journal, 06/11/2017). That said, Hana had inferred from students' attendance patterns that since they usually had their questions answered in GH meetings with a TA (three times per week), "sometimes no one turned up" in her regular office hours unless the session was about the unit review for assignments (journal, 06/23/2017). This interesting reflection indicates the timely and personalized support that synchronous tools can offer to foster stakeholders' online learning/teaching experiences (Authors, 2015a, 2015b). As Hana stated,

GH meetings seems to be functioning. No student asked me by email about the course content throughout the term. Two students used GD's comment function when they needed my quick response. Consequently, the discussion board on BB was never used for any Unit (journal, 07/05/2017).

\section{VT project: The "aha moment"}

As an asynchronous tool, VT allows students to read texts, hear native speaker's utterances, view images and videos, and write orthographic characters with fingertips, a stylus, or a cursor. The final VT project, a show-and-tell presentation on any topic related to Japanese people and culture, required students to leave video comments on peers' VT presentations. Hana was initially concerned about overburdening the students because of the inclusion of this new assignment. However, it turned out to be one of the most fruitful tasks, judging from students' presentational communicative performance (e.g., "...those who repeat recording are steadily improving." Journal, 06/22/2017), alignment of their interests and their language use, creativity and peer interaction (e.g., "...students who are motivated to practice are using VT more. They repeat, practice as they listen to the audio, etc. They are creatively making efforts...I was very moved." Journal, 06/14/2017). Surprisingly, no students complained about the added project workload in peer commenting, and some even commented that the VT project was the most enjoyable part of the course because they could express more freely and receive constructive feedback. As observed by Hana, "some students mentioned that VT takes time, but it seems that it is useful for practicing Japanese. For those who are motivated, it is a good tool. This is the area I could observe the most difference among students." (journal, 07/05/2017). She further delineated this "aha moment" in the interview as in:

I used the VT for the first time. It's a tremendously effective practice tool. It builds peer supports by showing students what/how the other students are studying...At the beginning, I wasn't sure if they could do it, since the course itself had so many assignments, and adding one more task at the end might be tough. I knew that VT assignments are time-consuming since many people claimed so in their journal and kept trying recording repeatedly until they felt comfortable to show to others. However, it was worthwhile! All projects were well-done, interesting, and exceeded my expectations. In addition, they could exchange their thoughts through peer comments. The VT final project may be the biggest success of the course! (interview, 08/10/2017) 


\section{Enrichment of teaching repertoire through reciprocal mentorship and apprenticeship in AR}

\section{Self-doubt of the novice: Advice seeking in apprenticeship}

As a novice teacher, Hana's vivid account of her first online teaching experience in the interview and deep reflections in her journal reveal a steep but dialectic learning curve. Gleaning from the qualitative data, the trend shows that she gravitated toward second guessing herself whether her approaches to the effectiveness of online delivery would work, especially in the beginning of her teaching. Her initial lack of confidence is evidenced in her verbatim: "I am not confident" or "[A]t the beginning, I was a bit overwhelmed." Her self-doubt that needed validation from student positive learning outcomes is also echoed in her interview, "...despite the short time intensive course, the students learned in good amounts. I was originally concerned how their speaking skills would be. But the 3 times/week GH session with TA and repetitious practice on the VT help tremendously" (08/10/2017). Additionally, Hana sought ongoing guidance from her mentor, Noriko, in order to resolve issues or ask for advice throughout her online teaching trajectory. A case in point is the new VT presentation project where Hana was initially apprehensive about whether this project would work in this online course and started to approach Noriko for guidance as illustrated in their journal exchanges (06/05/2017):

Hana: What kind of things do you think they can do [for VT presentation]? Any samples?

Noriko: ...I added you to my BB in spring 2015 so you can see some sample VTs. Most students did self-introduction and show-andtell. I prohibited reading [a cheat sheet during recording].

Hana: Thank you. How precisely do I have to teach the stroke order of hiragana?

Noriko: No need to be too picky. How about showing a set of representative mistakes (anonymously), add comments or arrows in different colors, and show them on the VT?

Hana: Okay. I will compile a list of problematic characters to alert them. VT is great because we can show the stroke order, too [using the doodling feature].

The dialogue journal between Hana and Noriko provides a third space for Hana to exercise her apprenticeship and receive timely advice during her teaching practice in the virtual context. Without the personalized, one-on-one consultation, she would have gotten lost in self-doubt and her level of confidence dampened due to the lack of experience. Like her students, Hana needed the mentor's support of her teaching in every step of the way. This aspect is particularly paramount to novice teachers who start their online teaching practices, and to program supervisors who consider providing ongoing guided support in teacher training (Edwards and Burns, 2016a, 2016b; Banegas et al., 2013; Shibakawa, 2018; Wang and Zhang, 2014; Yuan and Burns, 2017). 


\section{Instructional adjustment through teacher self-evaluation.}

Sometimes teachers are too bombarded with lesson planning and other obligations to take time to conduct a systematic and committed documentation of self-evaluation for future improvement. In Hana's case, GD provides an interactive platform for her to dialogue with Noriko about all things related to her teaching and student learning. It is probably more so to Hana as she meticulously reflected on her observed teaching practice and on students' responses to lecture materials, assessment tasks and digital platforms. This "reflective teaching" manifested in the teaching log also serves as an avenue for her to document what was going on in this intensive online course and conduct self-evaluation that led to necessary instructional adjustments (Allwright, 2003; Burns, 2013; Goodnough, 2010).

When reflecting on students' performance in the first oral exam via GH, Hana critically evaluated her delivery of this task, followed by Noriko's feedback. She commented in this journal entry $(06 / 21 / 2017)$ that she should have employed certain strategies to facilitate the flow of the oral exam and to enhance students' oral performance. Nevertheless, she had discovered the usefulness of having both audio/video sessions recorded to help assess students' oral performance without being overwhelmed by juggling GH session recording and marking simultaneously:

Hana: I had two 10-minute breaks in the morning for adjusting the [oral exam] schedule, but [both were] used to complete two students' tests...I should have had more [breaks in between].

Noriko: Right. Because you are working at home, you can do laundry and cleaning [during the break], too.

Hana:

Hana: I was also planning to ask [them] how to say "a.m." and "p.m.," and how to pronounce 4 時 and 9 時. I had it in my memo, but forgot about it ... I was preoccupied by manual tasks such as video recording, audio recording, screenshare, grading.... So, I'm so glad that I have both video and audio recordings because I can review them again for grading later.

Noriko: Agree. Evaluating their performance objectively is difficult without video or audio recording.

This vignette is related to her observation of students' performance in the second oral exam that focused more on unscripted and authentic communication skills, which was different from the first one. It dawned on her that "Although TAs were doing a great job, they might have gone through the course pack and might not have a chance to work on [unscripted] communication. I could have given them more specific tasks and instructions for [authentic] communication" (08/10/2017).

Her ongoing reflective teaching practices is evidenced in her initial approach to keeping track of students' completion of unit tutorials as opposed to fully designating this task to TAs: “...In this past week, I was really concerned about the students' progress. I think I 
checked too frequently. I think I should have trusted my TAs" (journal, 06/05/2017). This take-away message not only helped her prioritize her time without being inundated by students' tutorial work, but also prepared her to become a better TA coordinator later. Based on the learning needs of students, she further realized the importance of conducting virtual orientation sessions to help students transition more smoothly into the online course: "One student asked me "what he/she should do" this morning. I think I should have held an orientation at a few different times" (06/05/2017). While most of the self-evaluations were incorporated into the adjustments of her teaching approaches (regarding student needs, TA coordination, lecture delivery and technology), others also fed into her online teaching toolkit and professional development. Hence, ongoing and systematic documentation of teacher self-evaluation and critical reflection is as important to help a novice teacher improve and grow as his/her actual teaching practice (Burns, 2007, 2010, 2011, 2015; Greene, 2006; Kemmis and McTaggart, 1988; Sowa, 2009).

\section{Virtual supervision: Mentor shadowing, debriefing and evaluating} In normal circumstances, teaching practicum involves the placement of the student teacher in a partner school, the mentor teacher's class observation, debriefing the strengths and weaknesses of the lesson delivery and evaluation of the mentee's actual practice in next class after prior suggestions were made. However, supervision is particularly challenging to both mentor and novice teachers in an online setting because class observation and debriefing are more cumbersome to conduct online than in a F2F setting. Hence, strategies that can facilitate the protocol execution and simulate F2F supervision practice are extremely helpful. To retain similar quality of supervision as in regular F2F classes, Noriko capitalized on the affordances of digital tools adopted in this online course for her "virtual class observation" (i.e., the recorded GH sessions and students' activities documented in VT projects and GD tutorials). Additionally, the GDenabled dialogue journal serves as a vehicle for systematic, ongoing and personalized supervision. One of the examples is when Noriko finished watching Hana's recorded GH session in students' first oral exam and asked Hana to justify her approach to asking students to read a short passage using the screenshare feature (journal, 06/21/23017):

Noriko: You used screenshare when letting the students read a short text. Was the size of characters, especially furigana, too small?

Hana: Maybe. My monitor is big, but if students use a small monitor, furigana could be hard to see. I'll see if we can use bold-face for furigana. ... I just realized that I can change the font size for furigana.

As Hana's supervisor, Noriko closely shadowed Hana's teaching practice via recorded course materials and lesson activities and offered feedback on her performance in debriefing sessions. Hana was expected to justify her teaching approaches in different teaching scenario(s) throughout the course as illustrated above. It not only ensures the sustainability of the course, but also the quality of teaching and moderation of student assessments (Allwright, 1997; Edwards and Burns, 2016a). During the debriefing sessions, Noriko provided modelling and strategies in those "teachable moments" as exemplified in the following scenarios: 
Before the first oral exam (journal, 06/20/2017):

Hana: I am currently uploading each student's video, so could you look at one or two and show me how you would grade them? The review sheet with rubric, which I shared with students, and the slides that the students saw during the exam are in the same folder. I will show you my preliminary grading because I'm not confident. Could you advise me with how to present questions/prompts, etc.

Noriko: Sure. I'll start tomorrow morning. I'll also work on [this TA's] GD if you share the folder with me.

After the first oral exam (journal, 06/21/2017):

Noriko: For the item, "Vocabulary," how do you evaluate?

Hana: I wanted to see if they knew just Basic Vocabulary or even those in Vocabulary Collection.

Noriko: Vocabulary Collection is for optional (not-required) words. In my case, I focused on Basic Vocabulary, prepared illustrations, pointed at each illustration and made my students say what it was. I'll show them to you later. Let me know what you think about it.

These episodes demonstrate how Noriko tracked Hana's teaching practices, debriefed the pros and cons, resolved her concerns, offered scaffolding strategies through modelling and evaluated the outcomes of her modified teaching. This rigorous teacher training, exercised in this online course, meets (if not surpasses) the standards of its F2F counterpart as well as feeds back into the professional development of the novice teacher. The final thematic pattern below further reveals how this practice benefits Noriko as the mentor and the future course development.

\section{Mutually inclusive mentorship: AR}

As the ongoing virtual supervision progressed, both Hana and Noriko gradually developed a strong bond through mutual respect and learning from each other. Amiable, encouraging and positive reinforcements offered by Noriko were woven through their exchanges of their professional journal entries, such as "Everyone finished the test with a smile. Great job!" (journal, 06/21/2017) or "I think your scaffolding was very helpful" (journal, 07/10/2017) to boost the confidence level. Hana frequently expressed her gratitude to Noriko for her hands-on guidance, such as "Thank you for reviewing all of them (student assignments). Your input was very useful, and I learned a lot. I also learned a lot from actually creating questions, conducting the exam, etc." (journal, 0621/2017). The mutual respect and complimenting are resonated in Noriko's response to Hana's appreciation of those "useful comments," such as "No, no. I am learning a lot from hearing your views as well" (07/11/2017).

Reciprocally, Noriko gained new perspectives in polishing her teaching, strengthening the curriculum and fostering teacher training from her committed and meticulous online supervision. On multiple occasions, Noriko expressed her appreciation for Hana's new 
take on teaching this online course, ranging from her detailed report on her students' progress (e.g., "Thank you for the information, which will be useful for designing a syllabus in the future", journal, 06/14/2017) to her interaction with students in VT (e.g., "[her] summative response to students' multiple VT comments was effective, especially when responding to each student's each comment was extremely time-consuming. This method should be adopted in the future," journal, 07/11/2017).

To both Hana and Noriko, one of the most valuable lessons is understanding that the crux of spontaneous communication, authentic language use and cultural relevance that underlie the ACTFL standards and guidelines should have been fully integrated and realised--be it a face-to-face or fully online setting. In their case, "spontaneous communication" as part of ACTFL's 5Cs that foregrounded the goals and the processes for this online course somehow flew under the radar. Not until they debriefed on the outcomes of the two oral exams did they both realize that the teachers' actual practices may have deviated from their original teaching goals. That is, when Noriko taught JPN 111 online in 2015 , she closely followed the 5 Cs and focused on the three communication modes (interpretive, interpersonal and presentational) as she had been doing in traditional face-to-face teaching. Thus, when she conducted the oral proficiency interviews (OPI) with her students, they were already familiar with the authentic oral practices with peers, TAs, and her. In addition, Noriko frequently adjusted her interview approach by providing both verbal and non-verbal cues to students during the oral exams whenever they appeared confused or needed more scaffolding. As such, her students didn't find the two oral exams as daunting or unexpected as did Hana's students. Since ACTFL-standards have been deeply internalized by Noriko and always incorporated in her syllabus for both face-to-face and online courses, she failed to acknowledge Hana's unfamiliarity with the criticality of ACTFL-standards and her inexperience in seamlessly implementing them in online content delivery, communicative activities and assessments. Thanks to Noriko's ongoing supervision, participant observation, and lesson debriefing during the AR process, she was able to develop a new realization in areas that still need improvement in 5Cs alignment and future teacher training (Alwright, 2003; Burns, 2010, 2011, 2015; Creswell, 2012).

Therefore, specifications of the 5Cs on the syllabus or lesson plans become simply superfluous if teachers do not constantly and critically reflect on whether their students are using the target language for meaningful and authentic communication, particularly in a fully online context. In Hana's case, although she adopted the same curriculum, the first oral exam was conducted in a more "scripted" fashion (e.g., asking students to read aloud a short passage). When Noriko told her the importance of having students demonstrate unrehearsed communication skills in oral exams, she consequently adopted a less scripted oral interview approach in the final oral exam. However, she noticed that students became even more "nervous" or "underperformed." Hana's reflection in her online teaching log urged Noriko to closely evaluate her students' videorecorded performances in their second oral exam. Noriko's observations of the videos and her reflections led her to conclude that students' oral performance slipped because they didn't expect this type of unscripted oral interview and Hana's scaffolding was not as organic and timely as Noriko's. Following Kemmis \& McTaggart's (1998) cyclical AR model, the two full AR 
cycles (illustrated in Figure 4) document these dialectic and context-responsive practices that help them fine-tune pedagogical plans for optimal teaching/learning outcomes:

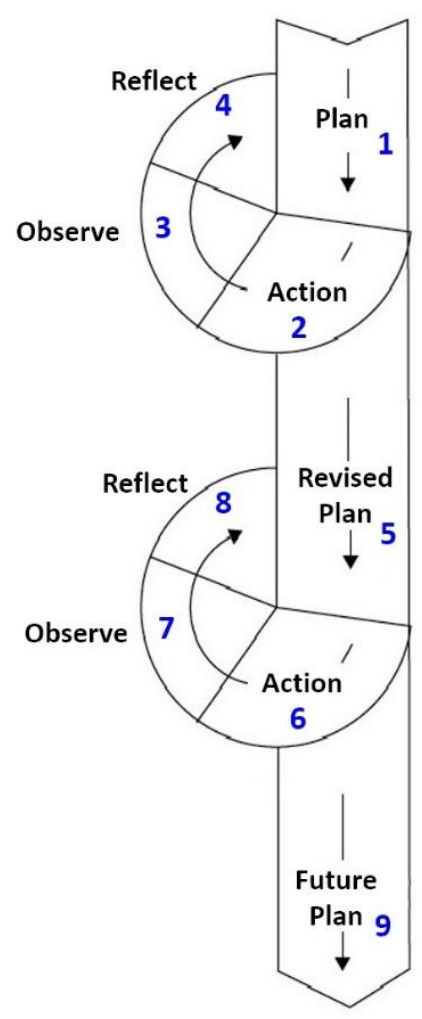

AR Cycle I

1. Plan: Hana planed the first oral exam by reviewing scripted interview questions and testing the Google Hangouts (GH) tool.

2. Action: Hana administered her first oral exam through $\mathrm{GH}$ videoconferencing.

3. Observe: Noriko observed students' videorecorded performance and noticed that they were based on scripted communication.

4. Reflect: Noriko realized that she had internalized the $5 \mathrm{Cs}$ so deeply that she failed to clearly convey the goals of the course to Hana; they debriefed on this aspect in dialogue journaling during virtual supervision

\section{AR Cycle II}

5. Plan: Taking Noriko's advice, Hana planned the second oral exam framed in authentic communication as the core of $5 \mathrm{Cs}$.

6. Action: Hana executed the second oral exam via $\mathrm{GH}$ videoconferencing.

7. Observe: Hana observed her students' performance and felt that they underperformed. Noriko observed students' videorecorded performances and noticed that they were not used to authentic communication and Hana was not providing them with effective scaffolding.

8. Reflect: Noriko realized that she failed to advise Hana on how to implement the ACTFL guidelines seamlessly during online teaching and how to offer scaffolding during communicative activities and oral exams. She also learned that Hana's case may also happen to other novice online Japanese teachers who try to bear both technicality and ACTFL's Guidelines in mind.

9. Future Plan: Hana expressed that she would like to learn more from the current AR and use the outcomes for improving the online course in the future with Noriko.

Figure 4. A visual representation of the AR cyclical processes of the implementation and alignment with the 5Cs (adapted from Kemmis \& McTaggart, 1998)

This salient aspect also prompted Noriko to critically reflect on her role as the supervisor and self-evaluate her mentoring approach, as shown in their final entry (07/11/2017):

Hana: I don't think students could have shown their true ability in this test.

Noriko: I should have told you the nature and the purpose of ACTFL 5Cs and the oral exams before the term. The 2 nd exam was quite different because you (kindly) took my advice, but I should have told you that it's better to start using simpler words at the beginning for warming up and gradually give harder words. However, I learned a lot from this experience, too. I've been teaching for more than 20 years, but I still have new discoveries for teaching, testing, class management, etc. every year. They involve dynamic and complex concepts, and they make students to be the teachers' (our) teachers. 
Noriko's self-guilt over her failure of clearly conveying to Hana "the nature and the purpose of ACTFL 5Cs and the oral exams" before the course started indicates that Noriko had internalized ACTFL standards to the extent that she overlooked Hana's unfamiliarity with implementing the 5Cs during online supervision. It is particularly the case when technical aspects would impact the effectiveness of tasks grounded in 5Cs and delivered fully online (Author, 2017). Mentoring a novice teacher framed in AR had offered Noriko a precious opportunity to critically reflect on the "whys" and the "hows" of standard-based, performance-driven, and technology-enhanced teaching, thus reinvigorating her own teaching and mentoring practices (Allwright, 1997; Edwards and Burns, 2016a).

Noriko's critical self-reflection and evaluation also mirrors the mutual benefits of online supervision in AR. Not only had Hana grown through her teaching practices shadowed by Noriko, Noriko had learned valuably as to improving the standard-based online curriculum from this mentoring experience. As active teacher practitioners, they virtually observed the class and lesson activities, debriefed what worked or didn't work, modified and tried out instructional strategies, re-evaluated student learning outcomes and fed back into the curriculum design for future improvement (Banegas et al., 2013; Sowa, 2009; Shibakawa, 2018). Gradually, Hana transformed from the novice frequently needing the mentor scaffolds to the experienced who could contribute her insights (Edwards and Burns, 2016b; Greene, 2006; Yuan and Burns, 2017). Noriko reciprocally gained inspirations and new understandings in online teaching, thereby strengthening the sustainability in professional development and future teacher training (Allwright, 1997; Edwards and Burns, 2016a; Goodnough, 2010). The following verbatim voiced by Hana and followed by Noriko's note to herself illustrates the epitome of AR in a virtual context (journal, 07/11/2017):

Hana: You wrote earlier that you and [the other author] wanted to examine how a new teacher teaches this course and how different types of platforms are perceived by students. I'm very interested in these [areas]. If we can make a prototype of JPN 111, which is taught yearly, we can broaden the horizons of teachers who can teach such a course. I could not have done it without you and your teaching materials. If you could continue updating the course each year, it would be very helpful.

Noriko's note: There are numerous contributions made by Hana's new trials and experiences, especially because she had a research mind. The benefit of collaboration for the process of designing and fine-tuning an online course and engaging in action research was significant.

Indeed, Noriko had some opportunities to shadow teaching assistants and new teachers in conventional classroom-based settings; however, her supervising practices were not as fruitful as the current case. Some key factors led to this outcome. First, online journal dialoguing via Google Doc transcends time/space constraints, which enabled Noriko to observe Hana's teaching more extensively and holistically than limited teaching observations that had only taken place in classrooms. Second, online foreign language 
teaching is relatively new to most Japanese teachers, and thus vetoes the imbalanced power structure typically existing between experienced and novice teachers regarding how to use technology for teaching (Edwards and Burns, 2016b). This rebalances the mentorship-apprenticeship ecology and opens a more flexible channel for negotiation between both parties (Greene, 2006; Goodnough, 2010). Third, Hana's interest in AR and her willingness to improve the online course in the future, as evidenced in the excerpt above, motivated her to consistently document her teaching from multiple perspectives, raise questions related to online teaching practices, challenge current approaches that did not work, implement context-responsive interventions and seek ongoing advice from Noriko. This mutually inclusive mentorship framed by AR enabled both teachers' intersubjective changes especially in the implementation of ACTFL standards: Noriko learned how easily standards/guidelines can be overlooked during mentoring and the negative washback on the teacher and students; Hana had grown from a novice teacher who tried to be like her mentor to a capable teacher with more experience, confidence and a research-mind who was motivated to collaborate and contribute more to future AR research in order to improve online language teaching (Edwards and Burns, 2016a, 2016b; Rovegno and Pintos, 2017; Shibakawa, 2018; Yuan and Burns, 2017).

\section{DISCUSSION AND LIMITATION}

Findings drawn from this study are conducive to future curriculum design, content delivery and teacher training for online language courses. First, it demonstrates that psychological distance between the instructor and the students (Oliver et al., 2012) can be mitigated through appropriate integration of user-friendly and personalized digital tools, and that overcoming the time and distance constraints can lead to positive learning outcomes in an online language course (Authors 2015a, 2015b, 2017). Second, our research findings mirror that "benefits of involving a practitioner researcher includ[e] increased validity and reliability, enhanced findings dissemination, high peer interest in results, and immediate use of research results" (Garst et al., 2012: 27). As a practitioner, Hana's commitment to reflecting on her teaching practice, coupled with Noriko's participant observation, spark richer and more valuable information that shapes the professional development of the team members and offers evidence-based recommendations responsive to the urgent needs of the course (Allwright, 1997; Banegas et al., 2013; Edwards and Burns, 2016a; Sowa, 2009; Yuan and Burns, 2017). The local knowledge, insider resources and skill sets co-constructed during the ongoing and dynamic AR process reinforce capacity building and valid results, adding authenticity and accountability to research and practice (Burns, 2011, 2013; Creswell, 2012; Wang and Zhang, 2014).

Above all, both the novice and mentor teachers' professional lives were transformed and empowered: their context-responsive actions led to the tight-knit AR implementation for distance education, sustainability for curriculum design, technology-facilitated tasks and course evaluation and professional development modules for online teacher training (Allwright, 1997; Edwards and Burns, 2016a; Kemmis and McTaggart, 1988). More importantly, the usefulness of reflective journal exchanges and virtual class observations 
provide ongoing debriefing, evaluation and moderation for both practitioners (Burns, 2015). This scholarly practice in action offers a viable model for conducting AR in online language programs.

Taken together, AR was deemed appropriate to our researched setting and responsive to the genuine needs of the course design and future teacher training, thereby enhancing the face validity, practicality and sustainability in its own right (Garst et al., 2012). Noteworthy is that AR "is not intended to be generalized. It is situated, or contextdependent" (Mackey and Gass, 2015: 270). That said, context-specific insights drawn from each AR study can add to a better understanding of unique dimensions in language teaching that tends to be complex, fluid and nuanced. With a systematic and well-planned research design that considers "trustworthiness," AR findings can still be as insightful and transferable to a wider community--they inspire and propel like-minded teacher researchers to reflect on their own practices (Burns, 2015). Also, Creswell (2012: 593) argues that the quality of an AR study is based on evaluating "... whether it addresses a practical issue, involves the collection of multiple sources of data, proceeds with collaboration and respect for participants, advances a path of action ...reflects both the researcher's and the participants' growth toward improved changes to practice". Our AR study has managed to meet these criteria and achieve the end goal. Nonetheless, the implicit limitation of our study is the tendency of mentor teachers to inevitably impose their own teaching beliefs on novices' teaching practices to some extent, despite researcher-practitioner negotiability still put in action and researcher reflexivity acknowledged during the AR process (Banegas et al., 2013; Yuan and Burns, 2017).

\section{IMPLICATIONS and CONCLUSION}

The current study documents how a novice Japanese instructor navigated through her first online teaching in an intensive summer Japanese beginner course while being mentored by an experienced Japanese teacher researcher. Their exchanged journal entries serve as useful evidence of tracking Hana's online teaching practices, strengthened by Noriko's ongoing supervision and evaluation during virtual class observation. Guided by AR, the novice teacher had ample opportunities to discuss with her mentor the lesson planning and task delivery, raise issues arising from online teaching, seek advice, implement the adjusted instructional approaches, re-evaluate the results and refine her teaching repertoire. Class observation and supervision were proven to be feasible in a virtual setting, evidenced in recorded student work (submitted assignments and online activities), documented teaching episodes (teacher-student interaction in digital platforms) and teacher evaluation (novice's teaching log, mentor supervision comments and debriefing notes).

Worth noting is the new understandings and knowledge gained by both practitioners during the AR process: the novice teacher learned the importance of integrating the $5 \mathrm{Cs}$ in each component of teaching in order for the targeted communication modes to take place; the mentor teacher realized the primacy of reassuring the seamless implementation of 5Cs in an online setting and recognizing students' potential in accomplishing meaningful, engaging communicative tasks using appropriate digital tools. Finally, both 
the novice and mentor teachers negotiated their professional identities during the course of online practitionership. Through critical and recursive journal dialoguing, they jointly de/reconstructed their teaching principles in shaping the pedagogy, spawning strategies to tackle existing/anticipated challenges, reflecting more deeply on lesson delivery and results, gaining a better sense of agency in transforming from a novice to an experienced (Edwards and Burns, 2016a, 2016b; Goodnough, 2010; Yuan and Burns, 2017). As such, AR engagement could be empowering for both the teacher and researcher as they "pushed, stretched, and challenged each other's perspectives through discussion, debate and other dialectic process" (Garst et al., 2012: 28). The end product, therefore, strengthens the quality of course delivery, teacher training and program sustainability for online foreign language programs.

\section{NOTES}

1. The names of the participants are in pseudonym to respect their privacy.

2. As reported in the AR literature, the actual AR practice is generally quite "messy," "interwoven" and goes beyond a clean sequential cycle (Burns, 2007, 2011). It is therefore difficult to pinpoint the exact number of cycles as each action spirals back and forth within and across phases with "unanticipated variations and reiterations in the process" (Burns, 2015: 189). Kemmis and McTaggart's (1988) AR model provides a starting point for teacher practitioners who are new to AR, as in our case.

\section{REFERENCES}

Authors (2015a)

Authors (2015b)

Authors (2017)

ACTFL (2015) World-readiness standards for learning languages. Available at: www.actfl.org/publications/all/world-readiness-standards-learning-languages (accessed 15 January 2019).

Adair-Hauck B and Troyan JJ (2013) A descriptive and co-constructive approach to integrated performance assessment feedback. Foreign Language Annals 46(1), $23-44$.

Allwright D (1997) Quality and sustainability in teacher-research. TESOL Quarterly 31(2), 368-370.

Allwright D (2003) Exploratory practice: Rethinking practitioner research in language teaching. Language Teaching Research 7(2), 113-141.

Allwright RL and Bailey KM (1991) Focus on the Language Classroom: An Introduction to Classroom Research for Language Researchers. Cambridge, UK: Cambridge University Press. 
Banegas D, Pavese A, Velázquez A and Vélez SM (2013) Teacher professional development through collaborative action research: Impact on foreign Englishlanguage teaching and learning. Educational Action Research 21(2), 185-201.

Blake R (2013) Brave New Digital Classroom: Technology and Foreign Language Learning (2nd ed). Washington, DC: Georgetown University Press.

Burns A (2007) Action research: Contributions and further directions in ELT. In Cummins J and Davison C (eds) International Handbook of English Language Teaching, Vol. 15. Boston, MA: Springer, pp. 987-1002.

Burns A (2010) Doing Action Research in English Language Teaching: A Guide for Practitioners. New York: Routledge.

Burns A (2011) Action research in the field of second language teaching and research. In Hinkel E (ed) Handbook of Research in Second Language Teaching and Learning, Vol II. New York: Routledge, pp.237-253.

Burns A (2013) Innovation through action research and teacher-initiated change. In Highland $\mathrm{K}$ and Wong LLC (eds) Innovation and Change in English Language Education. Abingdon: Routledge, pp.106-121.

Burns A (2015) Action research. In Paltridge B and Phakiti A (eds) Research Methods in Applied Linguistics: A Practical Resource, London: Bloomsbury Publishing, pp.187-204.

Cornwell S (1999) Interview with Anne Burns and Graham Crookes. The Language Teacher 23(12), 5-10.

Creswell J W (2012) Educational Research: Planning, Conducting, and Evaluating Quantitative and Qualitative Research (4th ed). Boston, MA: Pearson.

Creswell JW (2013) Qualitative Inquiry and Research Design: Choosing among Five Approaches (3rd ed). Thousand Oaks, CA: SAGE.

Crookes G (1993) Action research for second language teachers: Going beyond teacher research. Applied Linguistics 14(2), 130-144.

Edwards E and Burns A (2016a) Language teacher action research: Achieving sustainability. English Language Teaching Journal (ELT) 70(1), 6-15.

Edwards E and Burns A (2016b) Language teacher-researcher identity negotiation: An ecological perspective. TESOL Quarterly 50(3), 735-745.

Foreign Service Institute. FSI's experience with language learning. Available at: www.state.gov/m/fsi/sls/c78549.htm (accessed 15 January 2019).

Garst B, Franz NK, Peters B, Smith C and Baughman S (2012) Using single-case participatory action research as a methodology to explore Appalachian summer camp communities. PRISM: A Journal of Regional Engagement 1(1), 19-31. 
Goodnough K (2010) The role of action research in transforming teacher identity: Modes of belonging and ecological perspectives. Educational Action Research 18(2), 167-182.

Greene JC (2006) Evaluation, democracy and social change. In: Shaw IF, Greene JC and Mark MM (eds) The SAGE Handbook of Evaluation. London: SAGE, pp.118140.

Guichon N (2009) Training future language teachers to develop online tutors' competence through reflective analysis. ReCALL 21(2), 166-185.

Hartshorne R, Heafner TL and Petty TM (2013) Teacher Education Programs and Online Learning Tools: Innovations in Teacher Preparation. Hershey PA: Information Science Reference.

Jimenez JE and O'Shanahan I (2016) Effects of web-based training on Spanish preservice and in-service teacher knowledge and implicit beliefs on learning to read. Teaching and Teacher Education 55, 175-187.

Kataoka H (1986) Televised Japanese language program: The first year. Foreign Language Annals 19(6), 491- 498.

Kaiser DJ (2017) English language teaching in Uruguay. World Englishes 36(4), 744759.

Kemmis S and McTaggart R (1988) The Nature of Action Research: The Action Research Planner. Geelong: Deakin University Press.

Kubota R (1999) Learning Japanese via satellite in an American high school: A case study. Foreign Language Annals 32(4), 329-347.

Mackey A and Gass SM (2015) Second Language Research: Methodology and Design. New York: Routledge.

Merriam S (2009) Qualitative Research: A Guide to Design and Implementation. San Francisco, CA: Jossey-Bass.

Mori Y, Omori M and Sato K (2016) The impact of flipped online kanji instruction on written vocabulary learning for introductory and intermediate Japanese language students. Foreign Language Annals 49(4), 729-749.

Nesbitt D and Muller A (2016) Sustaining motivation for Japanese kanji learning: Can digital games help? The JALT CALL Journal 12(1), 23-41.

Nielson K, Gonzalez-Lloret M and Pinckney K (2008) Learning foreign languages at a distance: Characteristics of effective online courses. Available at: www.casl.umd.edu/wp-content/uploads/2016/02/LEARNING-FOREIGNLANGUAGES-AT-A-DISTANCE-tech-report-2009.pdf (accessed 4 October 2018). 
Oliver K, Kellogg S and Patel R (2012) An investigation into reported differences between online foreign language instruction and other subject areas in a virtual school. CALICO Journal 29(2), 269-296.

Rovegno S and Pintos V (2017) Building up authentic knowledge through teacher research. In: Banegas et al. (eds) Authenticity in ELT: Selected Papers from the 42nd FAAPI Conference, pp.10-21.

Shea P, Li CS, Swan K and Pickett A (2005) Developing learning community in online asynchronous college courses: The role of teaching presence. Journal of Asynchronous Learning Networks 9(4), 59-82.

Shibakawa M (2018) The effect of a teacher's belief system on online Japanese course development. In: Bastiaens T et al. (eds) Proceedings of EdMedia: World Conference on Educational Media and Technology, Amsterdam, Netherlands: Association for the Advancement of Computing in Education (AACE), pp.703708.

Sowa PA (2009) Understanding our learners and developing reflective practice: Conducting action research with English language learners. Teaching and Teacher Education 25(8), 1026-1032.

van Deusen-Scholl N (2015) Assessing outcomes in online foreign language education: What are key measures for success? Modern Language Journal 99(2), 398-400.

Wang Q and Zhang H (2014) Promoting teacher autonomy through universityschool collaborative action research. Language Teaching Research 18(2), 222241.

Warriner-Burke H (1990) Distance learning: What we don't know can hurt us. Foreign Language Annals 23(2), 129-133.

Yi H and Majima J (1993) The teacher-learner relationship and classroom interaction in distance learning: A case study of the Japanese language classes at an American high school. Foreign Language Annals 26(1), 21-30.

Yuan R and Burns A (2017) Teacher identity development through action research: A Chinese experience. Teachers and Teaching 23(6), 729-749. 